\title{
Relatos da caixa preta: representações como elemento da cultura escolar
}

\section{Reports of the black box: representations as elements of school culture}

\author{
Antonio Simplicio Almeida Neto ${ }^{1}$
}

\begin{abstract}
RESUMO
Neste artigo discute-se o conceito de "representação" na perspectiva proposta por Henri Lefebvre com o intuito de contribuir para o debate acerca das fontes e procedimentos metodológicos na análise das "culturas escolares", a partir de pesquisa realizada com professores de História que lecionaram em 1965-1975 e 1985-1995, sobre a dimensão utópica presente no ensino dessa disciplina. As representações, segundo a ótica aqui adotada, são entendidas não como elemento a ser superado na busca de uma verdade mais concreta, mas como um nível da realidade que se constitui como força, estimulando ou bloqueando desejos, levando ao imobilismo ou conformismo, disparando ações e freando impulsos, ensejando práticas criadoras ou meramente reprodutivas, produzindo simulacros ou anunciando a poiesis, o ato criativo.

Palavras-chave: representação; cultura escolar; disciplina escolar; ensino de história; utopia.
\end{abstract}

\begin{abstract}
This article discusses the concept of representation on the perspective offered by Henri Lefebvre, with the intention of put it in way to the discussion about the sources and methodological proceedings in the analysis of the "school culture". The discussion was made from a research made by using history teacher's interviews, who had taught between 1965-75

1 Professor do Departamento de Metodologia de Ensino da Universidade Federal de São Carlos, Brasil. Graduado em História pela Pontifícia Universidade Católica de São Paulo, Mestre em Didática e Doutor em História e Historiografia da Educação pela Faculdade de Educação da
\end{abstract} Universidade de São Paulo. 
and 1985-95, about the utopic dimension in the instruction of that subject. The representations, according the perspective used, are known not as an element to be overcomed in searching a more concretetruth, but like a strong level of reality, inciting or blocking desires, raising the immobilization or conformisms, causing actions and breaking impulses, causing creative practices or merely reproductive ones, producing simulacrum or annunciating the poiesis, the creative act.

Keywords: representations; school culture; school discipline; history teaching; utopia.

\section{Introdução}

Poiesis, do grego, significa criação, formação, ação de fazer algo. Sobre a educação e, mais especificamente, o ensino de História $^{2}$ é de se perguntar: são ou têm sido potencialmente criativos e criadores? Possuem uma poiesis? $\mathrm{O}$ ensino dessa disciplina tem possibilitado algum tipo de criação? Deveria potencializar atos criativos? Pensam os professores de História sobre aquilo que sua disciplina cria? Teriam esquecido ou nunca souberam? Teriam perdido a poiesis nos meandros do cotidiano escolar?

Um olhar de estranhamento para as atividades que seguimos fazendo cotidianamente provoca inquietação, perturba. Quando o professor se percebe num moto-contínuo, fazendo suas atividades diárias, repetidamente, mecanicamente, perdeu a poiesis de seu ofício, já não cria mais nada e a vida segue seu curso. Por vezes seguidas nos inquietamos assim, conosco e com outros professores, absortos em atividades estéreis, vazias de sentido, burocratizadas, automatizadas. É necessário então, um distanciamento, não necessariamente físico, mas crítico o suficiente para que se possa estranhar o naturalizado e enxergar onde não se olhava.

Nesse sentido, alguns relatos ${ }^{3}$ de professores, tomados como representações de suas práticas cotidianas e como as concebem, são bastante elucidativos para esquadrinharmos de maneira oblíqua essa espécie de "caixa preta" que é a escola e sua cultura, a poiesis, o ato criativo.

2 Utilizei a grafia História com "H" maiúsculo para me referir à disciplina escolar.

3 Os trechos de relatos aqui citados fazem parte de minha tese de doutorado: ALMEIDA NETO, Antonio S. de. Dimensão utópica nas representações sobre o ensino de história: memórias de professores. 310 p. Tese (Doutorado em Historiografia e História da Educação) - Faculdade de Educação da Universidade de São Paulo, Feusp, São Paulo, 2002. 


\section{Relatos da "caixa preta"}

I - Como no mito grego em que Sísifo, punido pelos deuses por seu ódio pela morte e paixão pela vida, empurra incansavelmente uma rocha montanha acima, que rola para baixo em pouco tempo, exigindo novo empenho e esforço num labor sem fim, a professora Sílvia ${ }^{4}$ olha para seu próprio trabalho e assim vê sua prática no dia a dia escolar:

É, ainda tenho. Tenho muita paixão, por isso que eu sofro muito dentro da escola, eu vivo me batendo, eu me bato muito, muito, muito, muito. Não tem um dia em que eu não derrube uma porta, disso eu estou cansada, de ser a 'moça problema', a que está sempre insatisfeita, então a minha auto-estima cai um pouco como educadora, entendeu?

Ao olhar para si e sua prática, a trajetória passada e presente, vê uma lutadora incansável a combater os professores por ela considerados "reacionários", "factuais" e "reprodutivistas", extrapolando os muros da escola para atuar no sindicato, participando de movimentos populares, lutando até contra sua própria faceta conservadora ou mais doutrinária. A imagem que constrói de si é a de uma espécie de guerreira solitária que não quer se...

[...] sentir um personagem, sou só o sujeito, não sou um personagem de história de ninguém, não quero ser a alegoria da escola de ninguém, sou só um sujeito que de vez em quando embica. De vez em quando bato com a cara na parede e é legal, olha pra trás e não tem ninguém junto, quando você sai tem dez juntos. "Vamos fazer isso?" "Vamos". "Vamos enfrentar?" "Vamos". Quando você olha tem vinte, trinta juntos, quando você chega parece que você está a dez quilômetros longe das pessoas.

4 Professora Sílvia (optei por utilizar nomes fictícios para as depoentes): 46 anos de idade (quando da realização da entrevista em setembro/2001). Graduada em Jornalismo pela Universidade de Mogi das Cruzes - UMG - Brasil (1979), História pela Pontifícia Universidade Católica de São Paulo - PUC-SP - Brasil (1989) e Pedagogia pela Universidade Bandeirante - Uniban - Brasil (1994). Lecionou História, Organização Social e Política Brasileira (OSPB), Educação Moral e Cívica (EMC) e Língua Portuguesa. Também lecionou no Mobral (alfabetização de adultos) e Febem (menores abandonados e infratores). Começou a lecionar História em 1983 na rede estadual de ensino de São Paulo e em 1990 na rede municipal de São Paulo. Militante do Partido dos Trabalhadores e sindicalista atuante do Sindicato dos Professores do Ensino Oficial do Estado de São Paulo - Apeoesp e Sindicato dos Profissionais em Educação do Ensino Municipal - Sinpeem, Brasil. 
Olhando para seu passado, a professora Sílvia entende que adotou uma prática de ensino francamente doutrinária, não se preocupando muito, segundo ela, com os aspectos metodológicos e científicos de uma aula de História. Sua doutrinação era de caráter político e se manifestava na escolha de textos, temas e abordagem,

\begin{abstract}
Ah!, Escolhia a dedo, aqueles textos bem... Solano Trindade, João Cabral de Mello Neto, falando de miséria, de pobreza, abordei muito o nordeste, "Grande Sertão, Veredas", muito essas coisas do nordeste, sabe assim? Malhando mesmo, pobreza, roubo, pegava muito a questão da terra, bem doutrinária mesmo. Esses textos mais de pastoral. Muito ligado, com certeza, na linguagem de..., a minha origem religiosa, a princípio. Da doutrinação quase que evangelizadora, "Temos que nos organizar no PT!", "Temos que organizar a classe trabalhadora!".
\end{abstract}

Sua atuação política não começou em sala de aula. Segundo ela, sempre foi meio "rebeldinha", desde quando, no início dos anos 1970, trabalhava como voluntária num projeto de promoção social envolvendo os municípios de Franco da Rocha, Caieiras e Francisco Morato, fazia parte da comunidade jovem cristã e "[...] já refletia muito politicamente nos evangelhos", lia Paulo Freire, lecionava alfabetização de adultos, organizava grupos de violeiros da comunidade.

Seu relato revela que sua prática de militância política foi se confundindo com o trabalho de professora de História, extrapolando os muros da escola e ganhando as ruas, levando os alunos para manifestações reivindicatórias e eventos políticos de maior envergadura. Lembra que:

[...] saía de moto, na garupa de um colega meu. Imagina a professora, com spray, ia panfletar a greve geral de 83?! Panfletei Franco da Rocha inteiro, todo mundo sabia no dia seguinte que era eu! A polícia ligou para o meu pai: "Sabemos que foi sua filha!" Você entendeu? Umas coisas assim. Militância mesmo. De pegar aluno..., assim..., diretor estava muito bravo dentro da escola com aluno crescendo cabeça, essas coisas todas, nossa..., de sair em passeata com aluno, contra o diretor. Uma professora, vamos pensar..., altamente orgânica. [...] Eu era doutrinária, meu! Eu preguei contra ditadura militar dentro da sala de aula! Levei aluno meu para lutar contra a ditadura, para buscar o Ortega, o líder da Nicarágua, fiz trabalho sobre a Nicarágua, a revolução nicaragüense. E ensaiei meus alunos de $5^{\text {a }}$ série a cantar: [cantando] "Adellante marchemos compañeros!...”. Estou te falando! 
II - Engajada, sim; doutrinária, não, sugeriu a professora Inês ${ }^{5}$ registrando que embora tivesse uma atuação politizada, nunca foi dada ao proselitismo político em sala de aula, prática que condenou com veemência, considerando essa postura um gesto de irresponsabilidade.

A imagem que tem de si e que procurou deixar para seus alunos é a da professora rígida e severa, o que parece não lhe incomodar. Pelo contrário, sente orgulho de, por essa questão, já ter entrado em choque com alunos e não the agrada ter que diminuir seu nível de exigência para se adequar à flexível realidade atual. Afirmou ter se espelhado em "boas diretoras", "pedagogas natas" e "professores muito interessantes" com quem trabalhou e trocava experiências ao longo da carreira, exemplos de rigor e compromisso que também pretende ser para seus alunos, pois considera que a "[...]melhor coisa que você pode ensinar para um aluno é o seu exemplo, de seriedade e de profissionalismo e isso eu sempre ensinei".

Atualmente, entre as coisas que lhe incomoda mais profundamente na educação, é a ausência de compromisso das novas gerações: alunos e professores. Em relação aos alunos observou que se abre uma lacuna cada vez maior entre seus valores e os deles. Sobre os professores observou com profunda indignação a má formação, a falta de profissionalismo e ética:

A maior parte dos valores desses meus alunos são assim e eu não consigo achar que esteja errada, então é muito difícil você estabelecer uma ponte com pessoas cujos valores você..., eu não vou dizer que eu considero errado, mas não são os meus valores, eu acho que o problema principal é esse. E os novos professores que estão chegando? Falta aquilo que se chama vocação e consciência profissional. Então, um dos maiores desgostos da minha vida foi quando eu entrei na minha escola do estado no último ano que eu dei aula e os professores jovens estavam jogando cartas na mesa dos professores. Você pode achar que não tem nada vender roupa na sala dos professores, vender produtos Avon, mas jogar carteado?! Aliás eles pararam de jogar assim que eu entrei, pra mim isso é... É assim, muita falta de ética, muita falta de comprometimento. Então o problema é o

5 Professora Inês: 55 anos de idade (quando da realização da entrevista em maio/2001), graduou-se em 1969 pela Faculdade de Filosofia, Ciências e Letras da Universidade de São Paulo - FFLC-USP (1966-1969). Cursou pós-graduação em antropologia, feito estudo de caso sobre uma tribo indígena, qualificou-se e desistiu no final, segundo a depoente, por achar seu trabalho "muito ruim". Lecionou História, Estudos Sociais, Educação Moral e Cívica (EMC) e Organização Social e Política Brasileira (OSPB). Leciona desde 1970, ainda estando na ativa, devido à "insuficiência da renda familiar". É professora (ensino médio e cursinho) e coordenadora da área de História de uma rede de escolas particulares na região de Campinas (SP). Lecionou na rede estadual de São Paulo, bairro da Casa Verde, de 1970 até 1995. 
seguinte: Para eles não têm muita culpa, pessoas completamente sem inclusive formação, nem em termos de conteúdo, acho que o mais grave é a ética, porque o conteúdo você pode aprender, mas a ética é uma coisa... [...] Mas me afasta, entendeu? Nos últimos dois anos, pela primeira vez na minha vida eu tenho pensado em parar, porque são alunos completamente sem limites, principalmente nas escolas particulares, que não sabem o que é ética.

Mais que uma mera diferença de atitudes, a indignação e inquietação da professora apontaram para a existência de uma cisão entre a sua geração e as novas, um hiato identificável, mas não preenchido.

III - Quando começou sua carreira nos anos 1980, a professora Rosa ${ }^{6}$, segundo declarou, já havia decidido que não seria uma "professora tradicional", o que a tem movido a trabalhar com questões significativas e procurar ser compreendida pelos alunos. Muito segura do que quer e do "como realizar", embora declare que a cada dia tem mais dúvidas, disse que sempre foi ela mesma quem escolheu e selecionou seu material, embora possa parecer "[...] meio autoritário, mas sempre me julguei mais capacitada para essa escolha".

Considera que sua principal característica como professora de História, fator que a diferencia de uma boa parcela de professores, é a isenção nas análises que procede, nunca impondo seu...

[...] ponto de vista para nenhum aluno, coisa que eu acho que os professores de História - a maior parte que eu conheço - defende o seu ponto de vista e reproduz na aula o seu ponto de vista e não assume que é o seu ponto de vista. Nesse sentido eu acho que a minha aula é particular, mas eu também não sei se os alunos percebem isso, se todos conseguem perceber que essa é a particular verdade da minha aula, ou se muitos prefeririam ter um professor tradicional, mas enfim, essa é uma particularidade minha, não é exclusiva minha, pelo amor de Deus, conheço muitos professores que também fazem isso, eu tento deixar isso como uma marca das minhas aulas.

6 Professora Rosa: 42 anos de idade (quando da realização da entrevista em abril/2001), cursou economia na Faculdade de Economia, Administração e Contabilidade da Universidade de São Paulo (FEAUSP), Brasil, por aproximadamente dois anos. Mudou para a Faculdade de Filosofia, Letras e Ciências Humanas da Universidade de São Paulo (FFLCH-USP), Brasil, e cursou história entre 1980-1985. Fez extensão acadêmica no PUC-Cogeae (Pontifícia Universidade Católica de São Paulo - Coordenadoria Geral de especialização, Aperfeiçoamento e Extensão-Brasil), "História, Sociedade e Cultura". Lecionou História e Organização Social e Política Brasileira (OSPB). Lecionou na rede estadual de educação de São Paulo entre 1986-1992. Leciona na Etesp (Escola Técnica Estadual - Brasil) desde 1994, na rede municipal de educação desde 1994 e em colégio particular desde 1995. 
Sem respostas conclusivas, demonstrou suas convicções para o trato com a história, mas se questionou sobre a percepção dos alunos sobre esse tratamento e se os mesmos não prefeririam "professores tradicionais", identificado como sendo aquele que dá a sua versão, a sua verdade ou assume como sua a versão do livro didático e cobra do aluno essa reprodução. Considerou que para os alunos o modelo ideal de professor de História é o "professor de cursinho", que "[...] faz piadinha da história, transforma a história numa coisa fácil de ser assimilada, e esse modelo para mim está muito distante de ser um modelo ideal, na verdade o meu modelo é aquele que eu tento seguir", qual seja, o professorpesquisador, que pesquisa sobre o ensino, seleciona e produz material segundo o que identifica ser os interesses dos alunos, um modelo longe de se realizar, em sua avaliação, pois falta tempo e recursos, mas que ela segue buscando.

\section{Representações e cultura escolar}

I. A metáfora da "caixa-preta" utilizada por Goodson? (1997, p. 93) para referir-se a "cultura escolar", em oposição à concepção que entende a escola como mera reprodutora de uma cultura que lhe é exterior, seja dos "conteúdos universais", seja da "ideologia dominante", relembrada por Julia (2001, p. 13), Vidal (2005, p. 25) e Viñao (2006, p. 86), sugere um campo de pesquisa pouco conhecido e de difícil investigação, entre outros fatores. Segundo Viñao (2006, p. 86), por apresentar “[...] sérios problemas teóricos, metodológicos e de fontes".

Ainda no referido texto, Viñao apresenta alguns dos “[...] elementos mais visíveis que conformam a chamada cultura escolar" passíveis de serem pesquisados: a) "os atores" (professores, pais, alunos e pessoal de administração e serviços); b) "os discursos e linguagens, conceitos e modos de comunicação utilizados no mundo acadêmico e escolar"; c) "os aspectos organizativos e institucionais" e d) a "cultura material da escola: seu entorno fisico-material e objetos (espaços edificados e não edificados, mobiliário, material didático e escolar, etc.)" (VINÃO, 2006, p. 74-5). Sobre o primeiro elemento sugerido, "atores", refere-se a importância de conhecer as "representações mentais" desses sujeitos que conformam a cultura escolar.

7 Goodson refere-se à "caixa preta" do currículo escolar no capítulo intitulado "O contexto das invenções culturais: aprendizagem e currículo".

8 Tradução livre, bem como demais citações de original em espanhol. 
É sobre essa questão, a das "representações", que trata esse artigo, intentando contribuir para ampliar o debate acerca da cultura escolar, de modo a nos possibilitar olhar...

[...] com mais atenção para a internalidade do trabalho escolar, nomeadamente nos momentos de conflito e ruptura. $\mathrm{O}$ funcionamento interno das escolas, o desenvolvimento do currículo, a construção do conhecimento escolar, a organização do quotidiano escolar, as vidas e as experiências dos alunos e professores (NÓVOA, mimeo., p. 5).

Em suas atividades diárias e nas relações e conflitos que se estabelecem, dentro e fora da escola, os professores seguem formulando suas noções a respeito de suas atividades diárias. É na relação entre esses sujeitos e seu objeto que se concebem essas formulações da prática, suas concepções sobre a vivência, um nível de conhecimento que se estabelece na forma de representações sobre o real, sobre o ensino, suas potencialidades, projetos, possibilidades de transformação socioeconômica, a permanência de ideais, conservação, surgimento de novas perspectivas, devaneios e decepções, restauração e ceticismo.

Indignar-se com alunos, decepcionar-se com professores, caminhar solitário, emocionar-se, vibrar com a atividade bem feita, promover a reflexão, impedir gestos, formar a criticidade, selecionar textos, produzir materiais, censurar-se, mobilizar alunos, hesitar. Eis algumas das práticas efetuadas pelos professores em seu cotidiano, como demonstram os relatos, e que também são expressões das ações implementadas pelos professores, daquilo que pensam que fizeram ou não fizeram, com as decorrências advindas e seus desdobramentos. São fatos e palavras: representações.

A teoria crítica das representações apresentada por Henri Lefebvre, em " $\mathrm{La}$ Presencia e la Ausencia” traz tento ao tema lembrando que diferentes autores que trataram da questão das representações o fizeram tomando-a por elemento a ser superado ou transcendido, já que o entendia como ilusório, errado e irreal. Evocando o exemplo da publicidade comercial e da propaganda política, com sua eficácia em produzir imagens, necessidades e motivações, propõe, diferentemente, tratar as representações como existentes e reais, pois possuem uma força na sociedade que é real e não pode ser negada. Sobre o dilema em questão, afirma que "[...] as representações não são nem falsas e nem verdadeiras, senão, falsas ou verdadeiras: verdadeiras como respostas a problemas 'reais' e falsas como dissimuladoras das finalidades 'reais"' (LEFEBVRE, 1983, p. 62). 
Devemos, então, compreender as representações sem a pretensão e ilusão de rechaçá-las, entendendo o processo pelo qual se formam, ganham força, circulam e deslocam o representado, sobreposto por seu representante através da representação. Lefebvre propõe que aquilo que se representa está presente e ausente na representação, que medeia essas duas ocorrências não excludentes, faces de uma mesma condição em existência mútua.

É nesse sentido que o representante está presente e ausente ao mesmo tempo na representação, agindo através de substituições e deslocamentos do real - para ele operações perpétuas (LEFEBVRE,1983, p. 34) - se multiplicando e manipulando-o. Para o autor, somente através da análise poderemos escapar das representações enganosas que ocorrem nos processos de representação e que são sua força, resultando em simulacros, repetições e situações miméticas. Sintetizando essa noção em Lefebvre, Lutfi afirma que o...

[...] papel da teoria crítica das representações não é destruí-las, pois não é possível viver e compreender uma situação sem representá-la. A filosofia, tradicionalmente, quer eliminar as representações. Sem elas, entretanto, só restam a morte e o nada. A teoria deve expor o poder da representação no mundo contemporâneo, deslindar os mecanismos de sua produção e permanência, e ao fazê-lo anunciar 'um pensamento novo e ativo já em marcha' (LUTFI, 1996, p. 96).

II. Para Lefebvre as representações formam-se no cotidiano, entendido como um nível da realidade social onde ocorrem a construção e transformação da sociedade, sendo que o desvelamento desse nível é a chave para a compreensão das representações. Essas se constituem como resultado das formulações teóricas - o concebido - e das experiências da vida social e prática, no plano individual e coletivo - o vivido. Apresentam-se como manifestações da relação do concebido com a vivência, emergindo da consciência individual e da correlação com as condições históricas particulares e gerais, é fruto do ser individual e social. Assim, entende-se que a representação é inerente ao viver e sua compreensão.

Mas se é no cotidiano que se formam as representações capazes de dissimular o vivido, através dos deslocamentos e substituições que se interpõem entre o representado e o representante, também é aí que se formulam as críticas, também na forma de representações, que combatem a homogeneidade e a unidade pretendidas pelas representações hegemônicas. Significa dizer que o cotidiano contém tanto as representações enganosas, que encobrem questões relevantes, como aquelas que apontam para o porvir, a utopia. Não as utopias abstratas, que 
ele trata de atacar, mas a utopia do possível, manifesta no descontentamento e desejo de transformação. É no cotidiano que se encontra, portanto, tanto a dissimulação como o gérmen da mudança.

Sua teoria crítica se oferece como possibilidade de fazer a análise das representações, de modo a entender as formas e os processos de formação e transformações das representações e como se dão as substituições e seus deslocamentos. Esse trabalho de análise implica considerarmos a gênese e a genealogia das representações, ou seja, sua origem e formação, buscando sua historicização, para que não as tomemos como noção ou ideia calcada no tempo presente ou como mero reflexo do passado, empobrecendo as possibilidades de entendimento das representações acerca dessa dimensão.

A busca desse entendimento, para Lefebvre, deve levar em conta o concebido (saber, ciências, conceitos teóricos) e o vivido (corpo, subjetividade, vivência social e coletiva), pois as representações não se definem somente pelo conhecimento, mas "[...] pela relação com uma vivência (uma presença)" (LEFEBVRE,,1983, p. 69). Para o autor, a representação é um terceiro termo que se forma a partir da díade concebido/vivido, a partir dessa relação. As representações são os elementos mediadores, que por vezes consolidam e modificam a díade, por outras circulam e desaparecem. Pensando-as socialmente, as representações formam-se da maneira como os grupos são e como se veem, como atuam e como pensam sua atuação, como sofrem e sonham o porvir. Afirma Lefebvre (1983, p. 94-95).

[...] [as] representações não são simples fatos, nem resultados compreensíveis por sua causa, nem simples efeitos. São fatos de palavra (ou se preferir de discurso) e de prática social. Portanto, as representações e suas tendências provêm de "sujeitos" sem reduzirem-se a uma subjetividade, e têm uma objetividade sem reduzirem-se a objetos sensíveis ou sociais, muito menos a "coisas". Esse modo de existência pode ser qualificado de ambíguo? Certamente.

Nessas instâncias, na relação entre vivido e concebido, é que poderemos flagrar as representações em seu uso, interferindo na realidade, produzindo movimentos e disputas, induzindo ações e relações. 


\section{Cultura escolar e poesis}

I. Os relatos citados inicialmente constituem-se como representações dos professores acerca de suas práticas. Mas não são simples "representações mentais", uma vez que munidos dessas representações implementavam ações no dia a dia das instituições de ensino onde atuaram, portanto, são representações que se traduzem em práticas, fatos e palavras. Por outro lado são também ressignificações, pois que são relatos memorialísticos, sobre o que fizeram ou consideram que fizeram, traduzindo, assim, aspectos da cultura escolar, como um dos elementos nesse...

[...] conjunto de teorias, idéias, princípios, normas, pautas, rituais, inércias, hábitos e práticas (formas de fazer e pensar, mentalidades e comportamentos) sedimentados ao longo do tempo em forma de tradições, regularidades e regras de jogo não interditas e compartilhadas por seus atores, no seio das instituições educativas (VIÑAO, 2006, p. 73).

[...] que, no entanto, como aponta enfaticamente Viñao, tem contado com a “"[...] cegueira dos historiadores frente a realidade cotidiana das instituições docentes e práticas educativas na aula". (VIÑAO, 2006, p. 86).

Os relatos aqui apresentados foram coletados junto a dois grupos de professoras de História ${ }^{9}$ que lecionaram entre 1965-1975 e 1985-1995, com o propósito de discutir as representações acerca da dimensão utópica presente no ensino dessa disciplina. Destaco da análise então realizada um aspecto que considero bastante ilustrativo do que venho aqui apresentando como proposição para pensar esse elemento da cultura escolar: representações acerca da própria prática.

A análise efetuada na perspectiva e entendimento aqui expostos, não teve por pretensão ou expectativa encontrar verdades factuais em depoimentos absolutamente objetivos. Mas sim compreendermos as representações de professores de História reveladas - através de seus relatos - em suas concepções, convicções, pretensões, anseios e frustrações sobre sua própria prática, ensejando ações e novas práticas cotidianas, bem ou mal sucedidas, interrompidas ou levadas a

9 Foram realizadas seis entrevistas com professoras de diversos perfis político-ideológicos, formação cultural-acadêmica e atuação, das quais destacamos alguns trechos mais significativos para esse artigo. 
termo, irrefletidas ou reelaboradas. Imprecisões contidas nos relatos revelam nuanças dessa relação temporal passado/presente que não podem ser entendidas à luz da dualidade falso/verdadeiro, sob pena de obstruir as possibilidades de compreensão, mas devem ser percebidas como manifestações das representações do presente que agora se projetam sobre as representações do passado.

Instadas a responder, entre outras questões, sobre o que consideravam ser o "professor ideal", sobressaiu aquilo que as professoras acreditavam transmitir a seus alunos, além dos conteúdos. A professora Rosa, por exemplo, ao falar do que supõe diferenciá-la dos demais professores de História, ponderou sobre a percepção dos alunos acerca de seu esforço para guardar-se de emitir opiniões sobre os documentos e textos que analisa, presumindo o entendimento de que a História ensinada não seja um punhado de fatos a serem decorados e nem simplesmente interpretados, mas entendidos como produção humana e, portanto, histórica.

A percepção de que formam "cidadãos críticos conscientes" foi a maior conviç̧ão dos entrevistados, com variações e indefinição do que seja "crítico", "cidadão" e "consciente". Para a professora Sílvia a "cidadania crítica" resvala na militância de esquerda, como indica seu relato, propiciada pela tomada de consciência dos problemas socioeconômicos brasileiros - miséria, racismo, distribuição de terra - através de uma interpretação marxista - luta de classes, posse e propriedade, meios de produção - entremeada por artigos de jornais, poesias, revistas.

Alunos não doutrinados e não sectários é o modelo de "cidadão crítico" que a professora Inês acredita formar há mais de trinta anos, seja pelo conteúdo ou forma, expressos em sua postura de seriedade e compromisso.

Analisando as propostas curriculares de História produzidas em diferentes estados brasileiros entre os anos de 1990 e 1995, gestadas na década anterior, Bittencourt afirma que as ideias de formar o "pensamento crítico" e a "postura crítica" não são novas na disciplina, estando presentes em propostas curriculares a partir dos anos 1950. Também o termo "cidadania" já era utilizado no início do século XX como objetivo para o ensino de História e para Estudos Sociais, seguindo o modelo norte americano, visando a compreensão da realidade para que o aluno - futuro cidadão do Estado democrático que se constituía-pudesse transformá-la, aperfeiçoando o sistema (BITTENCOURT, 1997, p. 21). Essas expressões, observa a autora, estão presentes em uma série de textos e são utilizadas para diferentes finalidades, associado predominantemente à cidadania política liberal, sendo que a "[...] idéia de cidadania social que abarca os conceitos de igualdades, de justiça, de diferenças, de lutas e de conquistas, de compromissos e de rupturas, tem sido apenas esboçada em algumas propostas" (BITTENCOURT, 1997, p. 22). 
Já em propostas alternativas - não oficiais - para o ensino de História produzidos nas décadas de 1970 e 1980, Cordeiro observa a existência de uma indefinição dos termos "cidadania" e "formar o cidadão", utilizados indistintamente, revelando diversos matizes, cabendo em diferentes discursos. $\mathrm{O}$ autor afirma que esses termos e algumas outras ideias, muito recorrentes no discurso sobre o ensino de História, acabaram por se constituir em verdadeiros chavões da disciplina:

Outras idéias-chaves do tipo de discurso que se vai formulando são: a do "homem como sujeito da História" e o da produção do conhecimento; a da associação íntima que deve haver entre ensino e pesquisa; e a do objetivo de formar o "pensamento crítico" dos alunos. Desse modo, com base nesse conjunto de afirmações, vai sendo composta uma espécie de jargão característico da área (CORDEIRO, 1994, p. 59).

A imprecisão e ambiguidade dos termos e expressões com que se procura definir os objetivos para o ensino de História nas propostas oficiais ou alternativas, também são verificadas nas representações dos professores sobre sua prática, o que pensam estar fazendo em sala de aula, que tipo de aluno supõem estar formando: o "cidadão", "militante", "patriota", "crítico", "não sectário".

Entendendo como essas representações se formam, pela vivência desses professores - não somente na escola, e são concebidas em sua prática, notamos que em alguns casos ocorrem repetições de jargões - representações valoradas ${ }^{10}$ - que vão se disseminando pelo meio escolar. Permanências de discursos que fizeram sentido em outras épocas e acabam sendo repetidos continuamente, mas também novos propósitos que se agregam e modificam antigas representações, revelando novas preocupações de seu tempo, num processo constante de transformação, como afirma Lefebvre (1983, p. 34) “[...] o deslocamento e a substituição da representação são operações perpétuas".

O equívoco, afirma Lefebvre (1983, p. 102), seria crermos na possibilidade de transcendência das representações para alcançar uma verdade mais concreta e complexa. Assim, cumpre entendermos essas representações como forças que podem provocar e estimular, mas também bloquear ações e inibir desejos, levando ao imobilismo e conformismo. Se a noção de "cidadania" ou "cidadão crítico" se apresenta como incerta, é sobre ela que certa dimensão utópica no ensino se erigiu, disparando ações e freando impulsos, ensejando práticas criadoras ou meramente reprodutivas.

10 Para Lefebvre (1983, p. 54) toda representação implica valoração, atribuição de valor ou, pelo inverso, desvalorização e depreciação. 
Das lembranças do cotidiano escolar, nos diferentes períodos discutidos, com suas práticas envolvendo diversas atividades em sala de aula, feiras culturais, estudos do meio, concursos e reuniões, emerge uma escola em constantes conflitos. Nos depoimentos coletados, a escola aparece como um local onde as relações entre os profissionais envolvidos nos processos de ensino-aprendizagem estão fadadas a ser estéreis, contribuindo para a estagnação pedagógica, cultural e política. Com exceção da professora Inês, que afirmou ter vivido momentos de intensa sintonia entre os professores, apesar de vociferar contra a falta de profissionalismo e ética dos novos, todos os demais mostraram um quadro, mais ou menos explícito, no qual o trabalho comum inexiste e as tentativas de impedimento são fartas, daí a insistente distinção intelectual sempre assinalada pela professora Rosa e a constante disposição da professora Sílvia para "derrubar portas".

Assim, trabalhos interdisciplinares abortam, reuniões sobre o ensino de História não ocorrem, projetos interdisciplinares não deslancham, atividades em execução são boicotadas. No entanto, esse modelo e postura de professor "conscientizador" e crítico que se baseia na confiança de que o pensamento, a informação e a cultura serão capazes de promover as transformações desejadas, cabendo ao professor um papel fundamental nesse processo, continua predominando.

II. O intento de conscientizar os alunos, infundindo-lhes capacidade crítica, tem sido um dos propósitos da chamada pedagogia "moderna". Afirma Tomaz Tadeu da Silva que:

A educação tal como a conhecemos hoje é a instituição moderna por excelência. Seu objetivo consiste em transmitir o conhecimento científico, em formar um ser humano supostamente racional e autônomo e em moldar o cidadão e a cidadã da moderna democracia representativa. É através desse sujeito racional, autônomo e democrático que se pode chegar ao ideal moderno de uma sociedade racional, progressista e democrática. (SILVA, 1999, p. 111-112).

Os professores têm incorporado esse papel, definido mais claramente com o iluminismo no século XVIII, particularmente os de História, dada a natureza política de sua disciplina: o professor que ilumina, educador-político, a inteligência formando e moldando, instigando a reação em cadeia que transformará a sociedade. 
Em oposição ao plano da modernidade e sua intenção crítica, ergueuse o discurso pós-moderno, por "[...] considerar a consciência como sempre parcial, fragmentada e incompleta, o discurso pós-moderno rejeita a idéia de educação como conscientização, como substituição de uma consciência ingênua por uma consciência crítica". (MOREIRA, 1997, p. 17). Lembra Silva que o “... pós-modernismo desconfia profundamente dos impulsos emancipadores e libertadores da pedagogia crítica. Em última análise, na origem desses impulsos está a mesma vontade de domínio e controle da epistemologia moderna" (SILVA, 1999, p. 115). O castelo argumentativo tradicionalmente erguido pelos professores para justificar o ensino de História parece ruir e o eco das vozes ainda pode ser escutado nos relatos: "estou meio perdida", "estou cansada", "era mais fácil ter certezas", "não tenho certeza de nada", "tenho pensado em parar", "hoje é muito desgastante", "não saberia mudar", "qual é o nosso verdadeiro papel?", "a perspectiva não é lá muito agradável", "hoje em dia eu não me posiciono", "não vejo perspectiva de mudar", "está muito vazio".

Não obstante a propriedade de algumas críticas levantadas contra as propostas da modernidade abre-se um imenso vazio entre suas promessas não realizadas e o não projeto do pós-modernismo. Questões como justiça social, liberdade, desigualdade, democracia estão nesse vazio aberto pelas teorizações pós-modernistas à espera de serem resgatadas e saldadas, mas para tanto se faz necessário redescobrir o papel da escola, da educação, do ensino de História.

Ocorre que, entre um modelo que se desfaz e outro que se constitui, os professores têm de se haver com seu cotidiano, vivenciando problemas concretos e concebendo proposições e alternativas. Em suas representações observamos uma dimensão utópica que se mantém, via de regra, no registro da modernidade, ainda que como slogan, retórica vazia, herança de um modelo falido ou como forma de sentir-se atuante, militante, agente transformador, ainda que de maneira oca, sem maior substância.

Em seus relatos parecem se investir desse ideal que, no entanto, com a não realização das promessas desejadas e o vazio que se instaura, têm gerado mal-estar e desalento, mas que, curiosamente, segue acompanhado de um discurso carregado de esperanças, ainda que de maneira vazia ou como forma de sentir-se atuante.

Encerradas nesse quadro, as professoras representam sua tarefa como ato solitário, adotando uma atuação cada vez mais individualizada, na qual o ensino depende exclusivamente de si mesmas: elas planejam, executam e avaliam, sem que ninguém saiba ou queira saber o processo e seus resultados. A professora Rosa isola-se ainda mais por se supor possuidora de uma melhor condição intelectual, a professora Inês pela diferença de valores e a professora Sílvia por colocar-se como uma quase mártir da causa escolar, arrebentando portas, convocando alunos, incitando colegas. 
Resulta daí um ensino no qual os problemas são vários e complexos, e as soluções pensadas como individuais, de tal forma que as professoras, diante dessa percepção, seguem cada qual buscando superar seus próprios problemas. As representações se constituem, assim, não só como desejo de mudança, mas também como frustração diante das dificuldades e impossibilidades de transposição dos obstáculos que se apresentam e se agravam diante da tão propalada crise da educação, potencializando-se frente às promessas de fáceis realizações que, tão afeitas ao mercado, são incorporadas à educação, redundando em novas representações.

Banalizada a crítica e a postura prospectiva, torna-se o professor um simulacro de si mesmo, embarcando em projetos que não são seus, investindo contra alvos que desconhece, pronunciando palavras que não acredita e não entende. Afora o desencanto, nota-se que essa dimensão utópica sofre um deslocamento. Mais que a imposição de uma "consciência crítica", que se oferece como um pacote pronto aos alunos, o que parece despontar como uma "nova" dimensão utópica, constituída como representações na cultura escolar, é a própria transmissão do desejo de querer transformar, desejo de passar adiante o próprio desejo, a poiesis, ato criativo.

\section{REFERÊNCIAS}

ALMEIDA NETO, Antonio S. de. Dimensão Utópica nas Representações Sobre o Ensino de História: Memórias de Professores. 310 p. Tese (Doutorado em Historiografia e História da Educação) - Faculdade de Educação da Universidade de São Paulo (Feusp), São Paulo, 2002.

BITTENCOURT, Circe Maria Fernandes. Capitalismo e Cidadania nas Atuais Propostas Curriculares de História. In: BITTENCOURT, Circe Maria Fernandes. (Org.). O Saber Histórico na Sala de Aula. São Paulo: Contexto, 1997.

CORDEIRO, Jaime Francisco P. A História no Centro do Debate: Da Crítica do Ensino ao Ensino Crítico. Dissertação (Mestrado) - Faculdade de Educação da USP, São Paulo, 1994.

GOODSON, Ivor F. A construção social do currículo. Lisboa: Educa, 1997.

JULIA, Dominique. "A cultura escolar como objeto histórico". Revista Brasileira de História da Educação, n. 1, p. 9-44, 2001. 
LEFEBVRE, Henri. La Presencia y la Ausencia: Contribuición a la Teoria de las Representaciones. México: Fondo de Cultura Económica, 1983.

LUTFI, Eulina Pacheco; SOCHACZEWSKI, Suzanna; JAHNEL, Teresa Cabral. As Representações e o Possível. In: MARTINS, José de Souza (Org.). Henri Lefebvre e o Retorno à Dialética. São Paulo: Hucitec, 1996.

MOREIRA, Antonio Flávio Barbosa. Currículo, Utopia e Pós-Modernidade. In: MOREIRA, Antonio Flávio Barbosa. Currículo: Questões Atuais. São Paulo: Papirus, 1997.

NÓVOA, António. História da Educação: Perspectivas Actuais. Mimeo.

SILVA, Tomaz Tadeu da. Documentos de Identidade. Uma Introdução às Teorias do Currículo. Belo Horizonte: Autêntica, 1999.

VIDAL, Diana. Culturas Escolares: estudos sobre práticas de leitura e escrita na escola pública primária (Brasil e França, final do século XIX). Campinas: Autores Associados, 2005.

VIÑAO-FRAGO, Antonio. Sistemas Educativos, Culturas Escolares y Reformas: Continuidades y Câmbios. Madrid: Morata, 2006.

Texto recebido em 22 de setembro de 2008.

Texto aprovado em 5 de março de 2009. 
